\title{
FUNGSI HUTAN MENURUT PERSEPSI MASYARAKAT DI DESA SEKITAR KPH BANYUWANGI SELATAN PERUM PERHUTANI DIVISI REGIONAL JAWA TIMUR
}

\author{
The Function of Forest According to Society Perception in Villages surrounding KPH Banyuwangi \\ South, Perum Perhutani Regional Division of East Java
}

\section{Omo Rusdiana ${ }^{1 *}$ dan Amelia Wardiman ${ }^{2}$}

(Diterima Agustus 2017/Disetujui Juni 2020)

\begin{abstract}
The issue of water scarcity is problem rife in various areas, especially in East Java. The aim of this study is to examine the causes of water scarcityin the village around the area Perum Perhutani South Banyuwangi KPH, Regional Division of East Java. In this study a head of village was appointment as key informance in villages were sampled to be interviewed.There are 30 respondents which represent each villages. Data were obtained from the representative with questionnaries, then analyzed descriptively. Based on the public preception of water scarcity during the dry season in Karangdoro and Sumbermulyo village is a slight different. Most of the villagers in Karangdoro didn't experience the presence of drought due to availability of DAM and water at the well to the needs of household, while Sumbermulyo villagers suffered of drought due to lack of DAM, and unavailable water wells in the dry seasons. The majority of villagers of Karangdoro and Sumbermulyo agreed that the forest serves as the optimal land cover for catchments water, the aesthetics of nature, and nature conservation.
\end{abstract}

Key words: forest function, perhutani, society perception, water, water scarcity

\section{PENDAHULUAN}

Hutan adalah sumberdaya alam yang multifungsi, serta memiliki peranan penting untuk menjaga kestabilan ekosistem di alam. Pengelolaan hutan yang diimbangi dengan budidaya hutan yang baik dan sesuai dengan fungsi hutan dapat membantu mengembalikan peranan dari hutan tersebut. Selain itu, upaya strategi dan rehabilitasi hutan juga diperlukan untuk mendukung pengelolaan hutan. Salah satu fungsi hutan yaitu sebagai penangkap air, karena adanya kumpulan pepohonan yang membantu proses penyerapan air ke dalam tanah yang dibantu oleh perakaran pohon.

Air merupakan kebutuhan utama bagi manusia dan juga pertumbuhan tanaman. Air terdapat di dalam tanah karena ditahan atau diserap oleh massa tanah, tertahan oleh lapisan kedap air, atau karena keadaan drainase yang kurang baik. Air dapat meresap dan ditahan oleh tanah karena adanya gaya kohesi, adhesi dan gravitasi (Hardjowigeno 2007).

Penyebab kelangkaan air sejauh ini karena faktor cuaca dan iklim, disamping itu adanya el nino juga mempengaruhi lamanya bulan kering di Indonesia. Selain itu meningkatnya aktivitas pembangunan dan jumlah penduduk, berakibat pada peningkatan kebutuhan air bersih. Kelangkaan air juga terasa hingga wilayah Provinsi Jawa Timur, khususnya Banyuwangi Selatan, peningkatan jumlah penduduk membawa banyak konsekuensi, diantaranya adalah kebutuhan air bersih

\footnotetext{
${ }^{1}$ Staf Pengajar Departemen Silvikultur, Fakultas Kehutanan dan Lingkungan Institut Pertanian Bogor

* Penulis korespondensi: e-mail: orusdiana@yahoo.com

2 Mahasiswa Departemen Silvikultur, Fakultas Kehutanan Institut Pertanian Bogor
}

yang semakin meningkat (Rusdiana 2001). Tujuan penelitian ini adalah mengkaji penyebab kelangkaan air di desa sekitar kawasan Perum Perhutani KPH Banyuwangi Selatan, Perum Perhutani Divisi Regional Jawa Timur.

\section{METODE PENELITIAN}

\section{Waktu dan Lokasi Penelitian}

Penelitian dilakukan di desa sekitar Perum Perhutani KPH Banyuwangi Selatan Divisi Regional Jawa Timur yaitu Desa Karangdoro, Kecamatan Tegalsari dan Desa Sumbermulyo, Kecamatan Pesanggaran, Kabupaten Banyuwangi, Jawa Timur pada bulan Maret 2016.

\section{Alat dan Objek Penelitian}

Alat yang digunakan dalam penelitian adalah perangkat laptop, lembar kuisioner, alat tulis, kamera, alat perekam, dan perangkat komputer seperti Microsoft word dan Microsoft excel. Objek yang diperlukan pada penelitian ini adalah masyarakat sekitar kawasan hutan dan data penduduk setempat.

\section{Prosedur Penelitian}

\section{Penentuan Lokasi Penelitian}

Metode yang digunakan dalam penentuan lokasi penelitian adalah metode purposive sampling yaitu pemilihan lokasi penelitian berdasarkan pertimbangan tertentu (Sugiyono 2012). Wilayah dengan jarak terdekat dari kawasan Perum Perhutani KPH Banyuwangi Selatan sebagai pertimbangan lokasi yang akan dipilih. 


\section{Teknik Wawancara}

Responden ditentukan dengan metode snowball, metode snowball adalah penunjukkan terlebih dahulu seseorang yang mampu memberikan informasi kunci (key informan) atau rekomendasinya dapat menunjukkan responden lainnya untuk diwawancarai. Penunjukkan key informan yaitu pada setiap kepala desa pada masingmasing desa yang telah ditentukan pada lokasi penelitian. Jumlah responden minimal 30 orang responden untuk mewakili seluruh populasi desa (Singarimbun dan Effendy 1995). Jumlah responden yang diwawancarai sebanyak 60 orang dengan masing-masing responden sebanyak 30 orang dari dua desa yang terpilih.

\section{HASIL DAN PEMBAHASAN}

\section{Kondisi Umum Lokasi Penelitian}

Secara geografis wilayah KPH Banyuwangi Selatan terletak di Kabupaten Banyuwangi. Kabupaten Banyuwangi terletak di ujung timur Pulau Jawa, daerahnya terbagi atas dataran tinggi yang berupa pegunungan dengan potensi berupa produksi pertanian, dan dataran rendah yang berupa garis pantai dengan potensi penghasilan berupa biota laut. Berdasarkan garis teritorialnya Banyuwangi terletak di antara $7^{\circ} 43^{\prime} 33^{\prime}$ sampai dengan $8^{\circ} 26^{\prime} 40^{\prime \prime}$ Lintang Selatan dan $113^{\circ} 53^{\prime}$ 40" sampai dengan $114^{\circ} 38^{\prime} 46^{\prime}$ B Bujur Timur.

Keadaan tanah di wilayah sekitar KPH Banyuwangi Selatan sebagian besar didominasi oleh tanah latosol coklat kemerahan dan litosol sedang dan sudah agak tua. Tipe iklim di wilayah Bagian Hutan Genteng dan Bagian Hutan Blambangan KPH Banyuwangi Selatan memiliki tipe iklim D sampai E yaitu tipe iklim kering menurut Schmidt dan Ferguson.

\section{Karakteristik Responden}

\section{Jenis Kelamin Responden}

Responden yang diwawancarai pada penelitian ini yaitu sebanyak 60 responden, dimana terbagi atas dua desa yang berada pada kawasan hutan KPH Banyuwangi Selatan yaitu Desa Karangdoro yang terletak pada Kecamatan Tegalsari dan Desa Sumbermulyo yang terletak pada Kecamatan Pesanggaran. Menurut data Badan Pusat Statistik (2015) jumlah warga Kecamatan Tegalsari dengan jenis kelamin laki-laki spada tahun

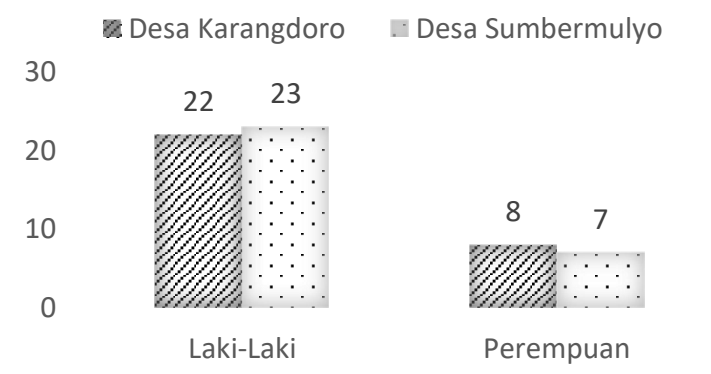

Gambar 1 Jumlah responden berdasarkan jenis kelamin di Desa Karangdoro dan Desa Sumbermulyo
2014 sebanyak 23446 jiwa dan jenis kelamin perempuan sebanyak 23446 jiwa. Jumlah warga Kecamatan Pesanggaran pada tahun 2014 dengan jenis kelamin lakilaki sebanyak 24921 jiwa dan perempuan sebanyak 24 326 jiwa. Jumlah responden berjenis kelamin laki-laki pada Desa Karangdoro sebanyak 22 orang dengan presentase sebesar $73.33 \%$ dan jenis kelamin perempuan sebanyak 8 orang dengan presentase sebesar $26.67 \%$. Sedangkan jumlah responden berjenis kelamin laki-laki pada Desa Sumbermulyo sebanyak 23 orang dengan presentase $76.67 \%$ dan jenis kelamin perempuan sebanyak 7 orang responden dengan presentase sebesar $23.33 \%$,

\section{Umur Responden}

Responden yang memberikan informasi mengenai ketersediaan air pada Desa Karangdoro sebagian besar berada pada sebaran umur 41 sampai 50 tahun dengan presentase sebesar 50\% sedangkan pada Desa Sumbermulyo sebagian besar berada pada sebaran umur 38 sampai 48 tahun dengan presentase sebesar $43.33 \%$.

\section{Tingkat Pendidikan Responden}

Desa Karangdoro memiliki persentase responden tertinggi pada tingkat pendidikan SMA sebesar 50\% atau 15 orang, sedangkan Desa Sumbermulyo memiliki persentase tingkat pendidikan terbanyak pada tingkat SMA sebesar $56.67 \%$ atau 17 orang. Menurut Lalamme (2004), pendidikan tinggi mengajarkan orang untuk berpikir lebih logis dan rasional, dapat melihat sebuah isu dari berbagai sisi sehingga dapat lebih melakukan analisis dan memecahkan suatu masalah. Selain itu, pendidikan tinggi memperbaiki keterampilan kognitif yang diperlukan untuk dapat terus belajar di luar sekolah.

\section{Jenis Pekerjaan Responden}

Responden yang diwawancarai memiliki berbagai macam pekerjaan antara lain sebagai buruh tani, perangkat desa, pegawai negeri sipil, dan wirausaha. Pada Desa Karangdoro sebesar 63\% atau 19 orang responden berprofesi sebagai buruh tani dan perangkat desa, sedangkan pada Desa Sumbermulyo sebesar 34\% atau 10 orang responden berprofesi sebagai buruh tani. Mayoritas masyarakat berprofesi sebagai buruh tani dari kedua desa di sekitar KPH Banyuwangi Selatan.

Tabel 1 Sebaran responden berdasarkan umur

\begin{tabular}{llll}
\hline Desa & $\begin{array}{l}\text { Selang } \\
\text { Umur }\end{array}$ & $\begin{array}{l}\text { Jumlah } \\
\text { (orang) }\end{array}$ & $\begin{array}{l}\text { Persentase } \\
(\%)\end{array}$ \\
\hline Karang doro & $22-31$ & 3 & 10 \\
& $32-40$ & 5 & 16.67 \\
& $41-50$ & 15 & 50 \\
& $51-59$ & 4 & 13.33 \\
& $60-69$ & 3 & 10 \\
\hline Total & & 30 & 100 \\
\hline Sumbermulyo & $19-28$ & 4 & 13.33 \\
& $29-38$ & 6 & 20 \\
& $39-48$ & 13 & 43.33 \\
& $49-58$ & 5 & 16.67 \\
& $59-67$ & 2 & 6.67 \\
\hline Total & & 30 & 100 \\
\hline
\end{tabular}




\section{Fungsi Hutan Menurut Masyarakat sekitar KPH Banyuwangi Selatan}

Pengetahuan masyarakat sekitar hutan yang berada di Desa Karangdoro dan Desa Sumbermulyo tentang fungsi hutan sangat beragam dalam memberikan manfaat pada lingkungan sekitar. Menurut Darusman (1993) hutan berfungsi sebagai pengatur tata air, yaitu dengan menahan air hujan guna mengurangi erosi permukaan dan meresapnya ke dalam tanah, dan selanjutnya dilepas secara teratur kedalam berbagai aliran air permukaan dan dibawah permukaan, sehingga distribusinya lebih baik bagi berbagai kepentingan di luar hutannya itu sendiri.

Pengetahuan masyarakat mengenai fungsi hutan cukup beragam, jawaban dari dua desa paling banyak yaitu dengan adanya hutan dapat menyimpan air, mencegah banjir, mencegah longsor, estetika alam dan menghasilkan oksigen.

Mayoritas masyarakat menjawab bahwa fungsi hutan sebagai penyimpan air dan perlu dilakukannya konservasi terhadap air. Konservasi air pada prinsipnya adalah penggunaan air hujan yang jatuh ke tanah seefisien mungkin dan mengatur waktu aliran agar tidak terjadi banjir yang merusak dan terdapat cukup air pada waktu musim kemarau (Arsyad 2006).

\section{Kelangkaan Air dan Penyebabnya menurut Masyarakat Sekitar KPH Banyuwangi Selatan}

Masyarakat Desa Karangdoro menyatakan bahwa sebesar $63 \%$ atau 19 orang tidak ada kelangkaan air, sedangkan $37 \%$ atau 11 orang menyatakan merasakan adanya kelangkaan air pada saat musim kemarau setiap tahunnya. Selain Desa Karangdoro masyarakat menyebutkan bahwa terdapat pula pada desa sekitar yang merasakan adanya kekeringan yaitu pada Desa Kalisuro dan juga Desa Karangmulyo. Masyarakat yang menyebutkan adanya kekeringan di desa tersebut karena adanya dampak dari alih fungsi hutan sejak lima tahun terakhir oleh masyarakat sekitar hutan pada bagian hulu yang menyebabkan adanya penurunan debit air sehingga saat musim kemarau air yang tersedia cenderung menurun. Tempo.co Banyuwangi (2014) Debit air di Banyuwangi menurun hingga $90 \%$ selama kemarau, DAM Karangdoro yang potensi debitnya mencapai 17 000 meter kubik saat ini mengalami penurunan hingga mencapai angka 4000 meter kubik.

Masyarakat Desa Sumbermulyo menyatakan bahwa sebesar $47 \%$ atau 14 orang tidak ada kelangkaan air, sedangkan $63 \%$ atau 16 orang menyatakan adanya kelangkaan air. Kelangkaan air terasa saat musim kemarau setiap tahunnya tak jauh berbeda dengan Desa Karangdoro, penyebabnya yaitu karena musim kemarau yang berkepanjangan, adanya penjarahan hutan, dan pengalihan fungsi hutan. Penjarahan hutan terbesar yang terjadi pada Perum Perhutani KPH Banyuwangi Selatan kurang lebih mencapai 12000 hektare dengan jumlah kurang lebih 500 pohon perhektare dengan rata-rata diameter pohon 1.2 meter. Selain itu adanya alih fungsi hutan yaitu hutan lindung menjadi pertambangan yang menggunakan lahan hutan lidung di Gunung Tumpang Pitu seluas hampir 2000 hektare, atau persisnya 1994 hektare yang akan digunakan sebagai kawasan pertambangan emas (Tempo.co Banyuwangi 2014). Beberapa masyarakat menilai bahwa sejak adanya kegiatan pengalihan fungsi hutan menjadi pertambangan menyebabkan berkurangnya air saat musim kemarau.

\section{Banjir dan Penyebabnya menurut Masyarakat sekitar KPH Banyuwangi Selatan}

Masyarakat menyebutkan bahwa sebanyak 60\% atau 18 orang reponden dari Desa Sumbermulyo, Kecamatan Pesanggaran membenarkan adanya kejadian banjir di kawasan sekitar KPH Banyuwangi Selatan (Gambar 2). Berdasarkan keterangan dari Kepala Camat Pesanggaran banjir terjadi karena adanya pertemuan sungai-sungai kecil pada muara sungai namun tidak dapat tertampung secara keseluruhan akibat adanya sedimentasi pada muara sungai.

Proses sedimentasi itu sendiri dalam konteks hubungan dengan sungai meliputi, penyempitan palung, erosi, transportasi sedimentas (transport sediment), pengendapan, dan pemadatan dari sedimen itu sendiri (Yang 2006). Hubungan sedimentasi dan banjir adalah dari proses sedimentasi tersebut menimbulkan pendangkalan dasar permukaan sungai sehingga kapasitas volume air sungai menjadi berkurang dan air meluap keluar sungai sehingga terjadinya banjir.

Proses terjadinya sedimentasi pada daerah sungai merupakan kejadian yang simultan yang dapat mengakibatkan pendangkalan pada dasar sungai dan perubahan elevasi sehingga akan mempengaruhi morfologi sungai, perubahan morfologi sungai tersebut sedikit banyak mempengaruhi ketersediaan air lingkungan sekitar, pada musim kemarau akan mengalami kekurangan air sedangkan pada musim hujan akan mengalami kebanjiran (Pangestu dan Haki 2013)

\section{Hubungan antara Penjarahan dan Pengalihan Fungsi Hutan terhadap Kejadian Banjir}

Air yang tercurah dari atmosfer sebelum sampai ke permukaan lahan yang berhutan akan diterima terlebih dahulu oleh tajuk. Air hujan akan mengalami pencegatan oleh tajuk, kemudian air hujan yang lolos dari cegatan disebut air lolos (through fall) dan mencapai lantai hutan, air hujan yang mencapai lantai hutan, dan air hujan yang mengalir melalui batang-batang pohon disebut aliran batang (stem flow) dan diteruskan hingga ke lantai hutan. Air hujan yang mencapai lantai hutan akan mengalami cegatan oleh lapisan serasah hutan. Air yang lolos dari cegatan serasah akan meresap ke lapisan tanah atas yang

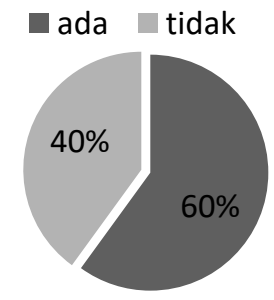

Gambar 2 Persentase banjir di Desa Sumbermulyo 
biasanya disebut air infiltrasi. Apabila kapasitas cegatan serasah telah jenuh dan infiltrasi mulai melambat, maka air akan menjadi aliran permukaan (Pudjiharta 2008).

Proses tersebut tidak akan terjadi jika adanya pengalihan fungsi hutan atau pembalakan liar yang mengurangi komposisi pohon. Air hujan yang jatuh pada lahan yang tidak ternaungi pohon hampir seluruhnya menjadi aliran air yang akhirnya masuk ke sungai, sehingga secara cepat menambah tingginya atau besarnya aliran sungai. Selain itu air hujan yang jatuh langsung ke lantai hutan menimbulkan erosi lapisan dimana badan material lapisan tanah paling atas terangkat dan terbawa oleh aliran permukaan. Erosi menyebabkan hilangnya lapisan tanah yang subur dan baik untuk pertumbuhan tanaman serta berkurangnya kemampuan tanah untuk meyerap dan menahan air (Arsyad 2006).

Teknik mencegah terjadinya erosi dapat menggunakan teknik konservasi tanah dan air. Menurut Subagyono et al. (2003), teknik konservasi tanah dan air dengan menggunakan metode vegetatif yaitu setiap pemanfaatan tanaman/vegetasi maupun sisa-sisa tanaman sebagai media pelindung tanah dari erosi, penghambat aliran permukaan, dan perbaikan sifat-sifat tanah baik fisik, kimia, dan biologi. Sedangkan Konservasi tanah mekanik adalah semua perlakuan fisik mekanis yang diberikan terhadap tanah, dan pembuatan bangunan yang ditujukan untuk mengurangi aliran permukaan dan erosi serta meningkatnya kelas kemampuan tanah.

\section{Jenis pohon yang di tanam perhutani}

Jenis yang ditanam oleh perum Perhutani Divisi Regional Jawa Timur KPH Banyuwangi Selatan yaitu jenis jati (Tectona grandis, L.f) yang berasal dari bibit unggul yang biasa dikenal dengan nama Jati Plus Perhutani (JPP). Jati terkenal sebagai kayu komersil bermutu tinggi dan cocok tumbuh di daerah musim kering agak panjang yaitu berkisar 3 sampai 6 bulan pertahun. Daerah-daerah yang ditumbuhi jati biasanya mempunyai tanah bertekstur sedang dengan $\mathrm{pH}$ netral hingga asam (Suriaty 2008).

Perhutani melaksanakan penanaman jati dengan permudaan buatan dalam hal ini KPH Banyuwangi Selatan menerapkan dengan perbanyakan tanaman dengan menggunakan stek pucuk. Permudaan alam pada tegakan jati walau mudah terjadi dan dapat membentuk tegakan murni setelah mengalami kebakaran serta mudah tumbuh tunas tunggak, tetapi permudaan alami ini jarang dilakukan karena akan menghasilkan kayu dengan

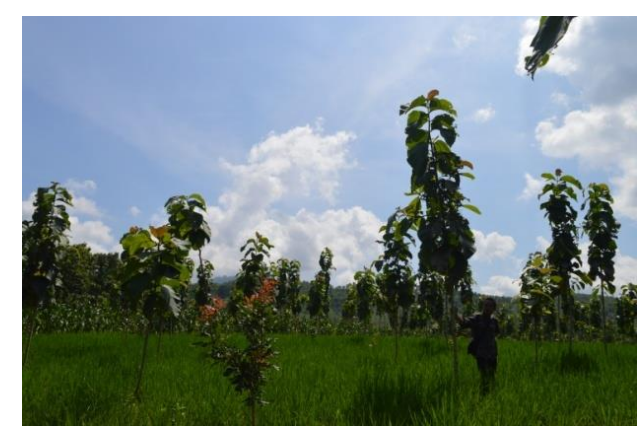

Gambar 3 Tanaman Jati stek pucuk kualitas yang rendah (Martawijaya et al.1981). Menurut Sumarna (2003), pengembangan tanaman jati untuk skala luas dan profesional perlu dirancang secara matang yang didahului dengan berbagai pengamatan meliputi letak lahan (topografi), kondisi ekologis, iklim, dan kesuburan lahan (tekstur dan struktur).

\section{SIMPULAN DAN SARAN}

\section{Simpulan}

Ketersediaan air di desa sekitar KPH Banyuwangi Selatan khususnya di Desa Karangdoro dan Desa Sumbermulyo mengalami penurunan debit saat musim kemarau. Hal ini dikarenakan adanya penjarahan hutan yang dilakukan secara luas serta adanya pengalihan fungsi hutan yaitu berupa pemukiman, perkebunan, dan pertambangan pada kawasan sekitar KPH Banyuwangi Selatan. Selain terjadinya kekeringan saat musim kemarau terdapat pula berdampak banjir saat musim penghujan. Pengalihan fungsi hutan dapat memberikan dampak yang cukup besar, karena hilangnya pohon mengakibatkan air hujan yang jatuh langsung ke lantai hutan dan menyebabkan aliran permukaan yang meningkatkan terbawanya lapisan tanah yang menyebabkan pendangkalan pada dasar permukaan sungai.

\section{Saran}

Sebaiknya masyarakat sekitar hutan ikut menjaga kelestarian hutan dan menjaga lingkungan sekitar hutan dari pembalakan liar agar tidak terjadi banjir pada musim penghujan dan krisis air bersih pada musim kemarau. Pendangkalan sungai akibat erosi dan sedimentasi dapat diminimalisir dengan penerapan teknik konservasi tanah dan air dengan cara metode vegetatif dengan penanaman di sekitar kawasan sungai atau secara mekanik. Pengalihan lahan sebaiknya dapat di rencanakan lebih matang agar dampak yang diberikan kepada lingkungan tidak begitu besar atau dengan membuat daerah resapan air pada lahan lain, sehingga menjaga kestabilan ekosistem lingkungan khususnya dalam kestabilan tata air

\section{DAFTAR PUSTAKA}

Arsyad S. 2006. Konservasi Tanah dan Air. Bogor (ID) : Institut Pertanian Bogor Press.

[BPS Banyuwangi] Badan Pusat Statistik Kabupaten Banyuwangi. 2015. Statistik Daerah Kecamatan Tegalsari 2015. Banyuwangi (ID): BPS Banyuwangi.

[BPS Banyuwangi] Badan Pusat Statistik Kabupaten Banyuwangi. 2015. Statistik Daerah Kecamatan Pesanggaran 2015. Banyuwangi(ID): BPS Banyuwangi.

Darusman D, Widada. 2004. Nilai ekonomi domestik dan irigasi pertanian: studi kasus di desa-desa sekitar kawasan Taman Nasional Gunung Halimun. Jurnal Manajemen Hutan. (10)1: 15-27. 
Hardjowigeno S. 2007. Ilmu Tanah. Jakarta (ID): Akademika Presindo.

Kompas.com. 23 Oktober 2015. Kemarau, 9 Kecamatan di Banyuwangi krisis air bersih [internet]. [diacu 2016 Juni 15]. Tersedia dari: https://regional.kompas.com/read/2015/10/23/12 535381/Kemarau.9.Kecamatan.di.Banyuwangi.K risis.Air.Bersih.

Laflamme L, Engstron K, Moller J, Hallquist J. 2004. Is perceived failure in schools performance a trigger of physical injury: A case-crossover study of children in Stockholm Country. Journal of Epidemiology. 55: 407-411.

Martawijaya, Kartasujana AI, Kadir K, Prawira SA. 1981. Atlas Kayu Indonesia Jilid I. Bogor (ID): Balai Penelitian Hasil Hutan. Forest Product Research Institut. Balai Penelitian dan Pengembangan Pertanian.

Pangestu H, Haki H. 2013. Analisis angkutan sedimen total pada Sungai Dawas Kabupaten Musi Banyuasin. Jurnal Teknik Sipil dan Lingkungan. (1)1: 103-109.

Pudjiharta A. 2008. Pengaruh pengelolaan hutan pada hidrologi. Info Hutan. (5)2: 141-150.

Rusdiana O. 2001. Kondisi dan masalah air di Pulau Jawa. Jurnal Manajemen Hutan Tropika. (7)1: 4954.

Singarimbun, Effendy. 1995. Metode Penelitian Survei. Jakarta (ID) : LP3ES.
Subagyono K, Marwanto S, Kurnia U. 2003. Teknik Konservasi Tanah secara Vegetatif. Bogor (ID) : Bbalai Penelitian Tanah.

Sugiyono. 2012. Memahami Penelitian Kuantitatif. Bandung (ID): Alfabeta.

Sumarna Y. 2003. Budidaya Jati. Jakarta (ID) : Penebar Swadaya.

Suriaty A. 2008. Studi laju degradasi hutan jati (Tectona grandis) KPH Bojonegoro Perum Perhutani Unit II Jawa Timur [skripsi]. Bogor(ID): Departemen Manajemen Hutan, Fakultas Kehutanan IPB.

Tempo.co Banyuwangi. 10 November 2014. Debit air 500 dam di Banyuwangi anjlok [internet]. [diacu 2016 Juni 14]. Tersedia dari : https://m.tempo.co/read/news/2014/11/10/206620 982/debit-air-500-dam-di-banyuwangi-anjlok.

Tempo.co Banyuwangi. 11 Desember 2014. $2000 \mathrm{Ha}$ hutan lindung di Banyuwangi jadi tambang [internet]. [diacu 2016 Juni 5]. Tersedia dari : https://m.tempo.co/read/news/2014/12/11/206627 872/2-000-ha-hutan-lindung-di-banyuwangi-jaditambang.

Teras Jatim.com. 15 November 2015. 8 wilayah di Banyuwangi rawan banjir dan longsor [internet]. [diacu 2016 Juni 14]. Tersedia dari : www.terasjatim.com/8-wilayah-di-banyuwangirawan-banjir-dan-longsor.

Yang Chih Ted. 2006. Sediment Transport Theory and Practice. Singapore (SIN) : The Mc Graw-Hill Companic. 